\title{
Computer Science Outreach Workshop and Interest Development: A Longitudinal Study
}

\author{
Antti Jussi LAKANEN, Ville ISOMÖTTÖNEN \\ University of Jyvaskyla, Faculty of Information Technology \\ P.O. Box 35, FI-40014, Finland \\ e-mail: antti-jussi.lakanen@jyu.fi,ville.isomottonen@jyu.fi
}

Received: January 2018

\begin{abstract}
This longitudinal study investigates the impact of an extra-curricular programming workshop in student interest development in computer science. The workshop was targeted at 12-18-year old youngsters. A survey was sent to all previous participants with a known home address; $31.5 \%$ responded the survey $(\mathrm{n}=197)$. This data was then combined with pre-workshop survey data, and analyzed with mixed methods. Positive development of interest was discovered for $57 \%$ of the respondents, of which nearly all attributed their interest increase to the workshop at least partly (92\%). Qualitative inspection revealed that the workshop provided three anchors that facilitated students' reengagement with programming and development of interest: disciplinary content, a concrete artifact built by students themselves, and tools. Neutral development and interest regress were also discovered, though the impact of the workshop on these interest trajectories remains unclear.
\end{abstract}

Key words: interest development, outreach, novice programming, game programming.

\section{Introduction}

Over the recent years, substantial effort has been invested in out-of-school learning environments and activities that aim at increasing youth's interest and careers in CS, and at improving students' understandings of CS concepts. Typically these activities use a strategy of introducing students to computational concepts and skills through a hands-on approach. Indications of the impact of these activities on the student's choice of a university major have been reported (McGill et al., 2015, 2016), while the need for more studies addressing the long-term impact is stated (McGill et al., 2016). Along with the widening adoption of the "CS for all" movement, it is important to understand how to maintain and develop student interest once it has been triggered. In-school CS classes as well as out-of-school outreach activities can provide opportunities for students to become engaged in computing, yet their effectiveness in terms of whether students' in- 
terests in computing careers actually develop has not been thoroughly studied (Decker and McGill, 2017).

This study adopted the four-phase model of interest development by Hidi and Renninger (2006b). Recent research referring to this model provides evidence that the development of interest contributes to learners' readiness to identify with a discipline (Renninger and Hidi, 2016, p. 4), and that interest appears to precede academic engagement (Reschly and Christenson, 2012). The model has recently received attention in computer science education (Ko and Davis, 2017; Scaico et al., 2017), the present educational context. These studies have investigated the impact of a particular intervention or educational tool on student interest. The present study complements the studies of this kind, while specifically focusing on a longitudinal aspect.

The main research question was: what is the impact of an extra-curricular programming workshop on student interest development in computer science. A survey was sent to all previous participants of the workshop with a known home address; 197 students $(31.5 \%)$ responded the survey. Students who responded had participated in the workshop during summers 2009-2016. The study also relied on a pre-questionnaire issued to workshop students during the first workshop day. Hence, in analyzing interest trajectories, the researchers could rely on both timely and retrospective students' accounts as to their interest stage in the past. Relying on these two data sets, the effect of prior programming experience on interest development was also studied.

\section{Interest Development}

This study draws on an established, yet still developing body of work related to the concept of interest. One of the most recognized theoretical models is the four-phase model of interest development (4PM) (Hidi and Renninger, 2006b). The model describes interest as a driver that makes people do things, while defining it as an entity that has potential to develop. Interest towards content starts developing from situational phases (triggered and maintained situational interest), where interest may arise in a short period of time but is more vulnerable to interference. Then, interest can develop towards individual phases (emerging and well-developed individual interest), which are more personal and persistent in nature. However, depending on the circumstances, any phase of interest can become dormant, regress to a previous phase, or disappear altogether. Hidi and Renninger (2006a, p. 112) particularly stressed that support is important in all phases of interest, and that interest is not likely to develop in isolation. The four phases of this model are depicted in Fig. 1.

The four-phase model has been referred to in several technology-related studies. Ko and Davis (2017) investigated the impact of mentoring on the adolescents' interest in computing. Mentoring played a more significant role in the participants' interests than gender, socio-economic status, or the number of programming languages encountered. The authors also noticed that the process of developing a relationship with a mentor contributed more to the participants' interest than having a mentor already. This observation originates in a 6-week class where the instructor attempted to develop mentoring 


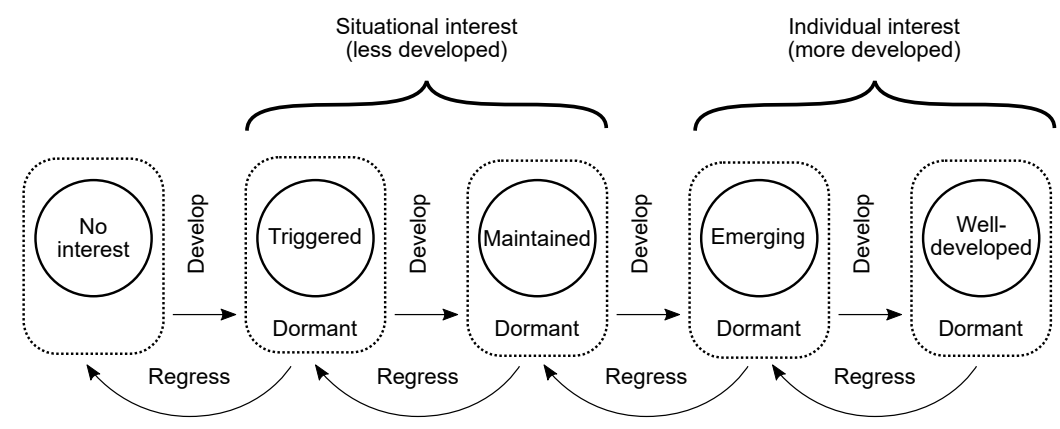

Fig. 1. The Four-Phase Model of Interest Development, adapted from Hidi and Renninger (2006b).

relationships with the participating students. The role of 4PM was generally to support a research hypothesis that mentoring activity was likely to contribute to interest development. The survey questions by which student interest was determined inquired after students' plans and rational for learning to code on a 7-point Likert scale.

Henriksen et al. (2015) studied the role of out-of-school experiences and other targeted recruitment activities in the choice to enter a STEM field. They reported indications of out-of-school experiences contributing to long-term choice processes. Drawing on Krapp (2002), the authors reasoned that such activities can serve as triggers for situational interest on which subsequent, more stable interest is based. An interesting observation was that youngsters valued institutions own information materials, which, the authors concluded, are thereby a rather cost-effective recruitment measure.

A related setting, in which 4PM has been referred to, is studies on female underrepresentation in STEM. Burns et al. (2016) focused on the role of empathy in developing 6th-grade girls' interest in STEM, and on the potential connections between interest, self-efficacy, belongingness, identity, and empathy. They observed that girls did not prefer empathy-related areas more than boys but rather indicated less interest in areas such as engines, games, designs, and patterns. Erete et al. (2016) based their project activities on narratives and concluded that relatable narratives may trigger situational interest.

Moreover, Beh et al. (2015) applied 4PM to technology learning with older adults as the target group and proposed self-determination theory as a bridge from situational interest to individual interest. Their specific focus was touch screen technology and its effects on the users' interest. The study thus treats interest development in the context of HCI research, a link that was discussed by Dousay (2014).

A systematic review by Potvin and Hasni (2014) on the youngsters' interest, motivation, and attitude (I/M/A) regarding science and technology summarized previous research. The review showed that attitude was the prevailing attribute studied. The concept of interest was referred to in 63 articles, but less than half of these studies included a definition of the concept. Hands-on experience and inquiry-based activities stood out as important means of intervention. The review also highlighted the importance of contextualization in terms of real-life relevance of classroom activities. Boy/girl differences were a frequent research topic, with the outcomes indicating that the gender preferences related to pedagogic contexts rather than to disciplines. Positive developments of $\mathrm{I} / \mathrm{M} / \mathrm{A}$ 
were attributed to cumulative positive experiences and concluded to be dependent on several attributes such as self-efficacy. Research-wise, the authors noted the traversal nature of the research reviewed, and called for longitudinal research.

\section{The Context: Five-day Game Programming Workshop}

A five-day, five hours a day, intensive programming workshop was developed. The workshop curriculum consisted of an introduction to computer programs, programming concepts (variables, loops, lists, arrays, ... ), as well as data structures and algorithms. Students also used a version control system, which mainly served as a shared code repository to allow participants experiment with the games developed by their peers. The content was heavily based on a game-based approach. Programming and computing concepts were introduced through direct instruction and worked examples (Sweller, 2006), which students utilized as skeletons for constructing their own computer games. The games were built using Jypeli game programming library, which was built in-house. Typically 20-30 students attended each workshop, and four to five workshops have been arranged every summer from 2009 to 2017; around nine hundred students have attended the workshops. Students were instructed by a responsible teacher (university teacher; faculty member) and assisted by 4-6 teaching assistants. The responsible teacher has also taught introductory programming (CS1) for university students for several years. The assistants were typically third or fourth year CS students.

A little less than half of the curriculum was allocated to short lecture-style teaching sessions that emphasized active learning, whereas the rest of the workshop hours were spent in computer labs where students programmed games that they had designed. During the lecture sessions, students were given, for example, pen-and-paper group assignments on algorithmic thinking. During the game-building phase, participants were intensively guided by the teaching team; because all students created their own games according to their personally made design, this part of the workshop experience was largely based on individual instruction. The workshop curriculum has remained roughly the same throughout the years.

\section{Method}

A longitudinal survey study was conducted to investigate how the workshop had affected the students' interest in CS.

\subsection{Data Collection}

The study drew on two questionnaires. A "retrospective questionnaire" - the main research instrument in this study - included questions about students' post-outreach programming activities, voluntary engagements, current higher education study status and 
Table 1

The number of responses to the retrospective survey according to the elapsed time between taking the workshop and responding to the survey

\begin{tabular}{lllllllll}
\hline Elapsed time (years) & 1 & 2 & 3 & 4 & 5 & 6 & 7 & 8 \\
Count & 29 & 29 & 20 & 20 & 28 & 21 & 31 & 14 \\
\hline
\end{tabular}

majors (or plans to make these choices), perceptions of the impact of the outreach on their CS activities and study choices, and demographics. Respondents were also requested to recall thoughts and feelings about their participation in the outreach. Instead of only asking respondents to rate or comment on the level of interest that they experience at a particular time ("How interested are you in CS"), items that provided data about the students' actual behavior or major enrollment were used. These were requested using both forced-choice items and open-ended items where students were able to freely describe their previous and ongoing CS activities.

An invitation to participate was sent to previous workshop participants whose postal addresses were known. Here, traditional mail was used because only a fraction of the valid e-mail addresses of the students were known, but the survey itself was a web questionnaire. A printed letter was also deemed a personal way to encourage participation. The recipients had taken the workshop between 2009 and 2016, and the retrospective survey was conducted in July 2017. Hence, the elapsed time between taking the workshop and responding to this survey varied from one year to eight years, being 4.3 years on average. Table 1 shows the number of responses according to the elapsed time.

The response rate to the retrospective questionnaire was $31.5 \%$ (197 out of 625$)$. The majority of the respondents, $91 \%$, were male. The proportion of female respondents was roughly the same as in the workshops, and hence the gender distribution of the sample represents the whole workshop population. The underrepresentation of female participants is acknowledged by the project team; reflections on gender imbalance are provided in Section 6.

Moreover, the data from a "pre-questionnaire" issued to all workshop participants during the first workshop day was used. The questionnaire items concerned prior programming experience, programming languages encountered, reasons for participating, general perceptions of programming, and perceived intention to apply for CS studies. Hence, the researchers were able to rely not only on the retrospective views of the respondents, but also on their earlier perceptions when analyzing interest prior to the workshop. The questions of both questionnaires are given in Appendix 7.

\subsection{Analysis}

Within-person analysis of the phases of interest were interpreted by three or two researchers independently. The cues and indicators of frequency and depth of any voluntary or independent engagement in computing activities were searched for in the retrospective questionnaire data. The prequestionnaire data was used to understand the baseline inter- 
est at the time of entering the workshop. If student had participated more than once, only the very first pre-questionnaire data was utilized. Thus, the analysis focused on both (1) the phase of initial interest prior to the workshop, and (2) the phase of current interest at the time of longitudinal surveying, after the student had participated once or more often in the workshops.

The interest coding scheme followed the characterizations of the theoretical framework (Renninger and Hidi, 2016, p. 13). A simplified scheme below gives the reader an overview of each phase:

- Phase 1: Short-term change in cognition and affect; reaction to a content or activity.

- Phase 2: Focused attention to a content, which persists, continues, or reoccurs over time.

- Phase 3: A beginning of relatively enduring state where a learner is likely to independently reengage with content over time.

- Phase 4: As phase 3, but more enduring; a learner self-regulates easily, works independently, and has stored knowledge and experiences of value.

In addition, Phase 0 was defined to refer to a completely nonexistent interest. As a rule of thumb, the initial interest was coded as Phase 1 , if the student had none or little background in programming, but, on the other hand, had not yet developed knowledge or voluntarily reengaged with computing. However, the initial interest was coded as Phase 0 if the student explicitly expressed that his / her incentive to participate was not related to the content. These students referred to external motives such as enthusiasm in games, having fun with friends, or urging by parents. In an unclear case, where either initial interest or current interest phase could not be interpreted, the state was left blank.

Data from 40 randomly selected students were coded by three raters. Interrater reliability was then assessed, and it indicated a quite high level of agreement: 0.806 Krippendorff's alpha. Through discussing the points of disagreement, the coding scheme was elaborated, and a different data set from 10 randomly selected students was coded by two (the authors) of the original three raters. A very high level of agreement was reached: 0.965 Krippendorff's alpha. Again, after discussing the codings, it was deemed acceptable that the first author alone coded the remaining of the data. Based on the these initial and final interest phase codes, the participants were further divided into those with increased interest, no change in interest, and regressed interest. These groups were qualitatively characterized, and correlation between prior programming experience and change of interest was calculated.

\subsection{Validity Considerations}

Questionnaires have inherent shortcomings such as short responses to individual open questions. This was counteracted by having numerous items in the questionnaires; then, data from non-direct questions could be utilized to support interpretations made from ones more directly indicating levels of interest. Students' descriptions of their experiences in working with CS content were often broad or cursory, and, for example, pos- 
sible reengagement with the content had to be interpreted through multiple open-ended questions. A more fine-grained tracking of interest could yield a description of possible fluctuations between the interest phases.

Renninger and Hidi (2011) commented on the lack of clear-cut guidelines for conceptualizing and measuring interest and its development. They specifically cautioned against using self-reports that directly request levels of interest in a given situation. This is because respondents might not be aware of triggering processes in the early phases of interest development. In the present study, we did not request students to directly evaluate their level of interest in pre- nor post-questionnaires. We instead used lots of questions that addressed actual programming-related behavior. On the other hand, we relied on the respondents' memory and ability to word their memories to describe their actions, feelings, and thoughts retrospectively. In the light of the abovementioned caution by Renninger and Hidi, we believe that thinking back (cf. use of memory) in retrospective survey, some time after the workshop, may have helped respondents conceptualize their feelings and valuations. Relatedly, memory has been argued to be plausible data by autoethnographers who return to study remembered, personally relevant experiences (Wall, 2008, pp. 45-46).

Cautiously speaking, this study allows for causal conclusions. The retrospective questionnaire included a Likert item that specifically asked whether the workshop had been an incentive for post-workshop activities. However, not only the summer workshop may have affected students' interest; there may exist other factors, such as encouragement from family members, whose effects were not studied.

The categorical variables related to interest played an important role in the data analysis. The sample size $(n=197)$ exceeds the minimum returned sample size for categorical data, with a high level of confidence $(95 \%$ or better), small margin of error $(5 \%$ or less), $\mathrm{p}=.50, \mathrm{t}=1.65$, in a population of 625 (Bartlett et al., 2001). The data may not reflect academic or socio-economic diversity in the local area. Therefore, it is fair to assume that the results of this study are generalizable only within the population of the workshop participants.

\section{Impact on Interest}

Based on the previously described multi-author analysis (see, Section 4.2), the participants exhibited interest trajectories ranging from regression to notable interest development. The frequencies of students in each interest phase are given in Fig. 2. There is a quite notable difference between the two observation points; while the phase 1 is clearly the mode of the initial interest, the final interest is bimodal (phase 2 and 3 ) and almost evenly spread across the scale. Descriptively, the phase mean increased from to 1.4 to 2.0. Related-samples Wilcoxon signed rank test (paired difference test) was used to assess whether the population mean ranks difference was statistically significant; the test supports rejecting the null hypothesis (the result is significant at $p<0.05$ ). It seems that in the initial point most participants possessed at least some personal incentive toward programming, as indicated by the high number of students in Phase 1. This seems natural in the outreach context where the workshops were targeted for young novice program- 


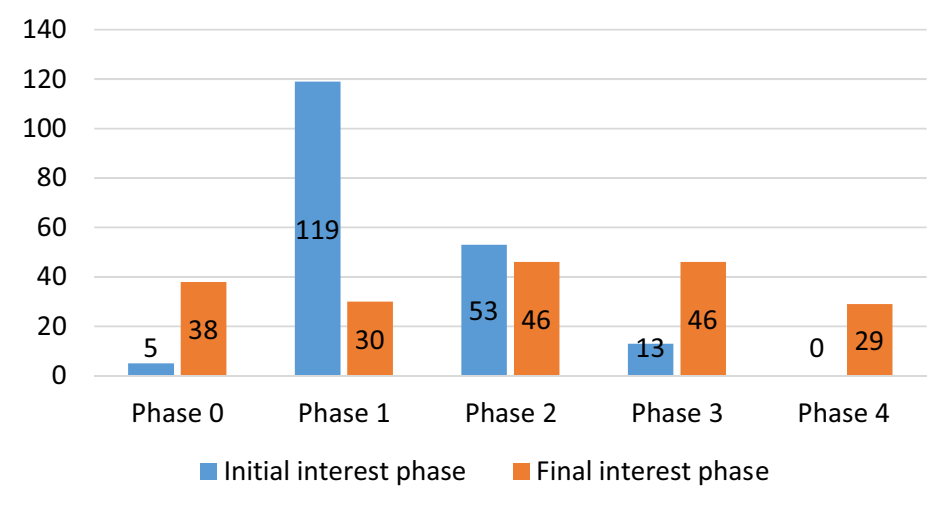

Fig. 2. Frequencies of initial and final interest phases. While Phase 1 (triggered situational interest) is most common initial phase, there is much more dispersion in the final interest.

mers. Correspondingly, it is unsurprising that there were initially only a handful of participants who demonstrated individual interest.

The most common development was a one phase development, concerning $40 \%$ $(\mathrm{n}=75)$ of the respondents. The frequencies of these interest trajectories were: $\mathrm{P} 1 \rightarrow \mathrm{P} 2$ : 36 students; $\mathrm{P} 2 \rightarrow \mathrm{P} 3: 26$ students; $\mathrm{P} 3 \rightarrow \mathrm{P} 4: 12$ students. 'P' is an abbreviation for 'Phase' in interest development.

The second most common development, or rather lack of development, was that the student remained in the interest phase were he or she was initially $(22 \%, n=42)$. More prominent increases were also quite common: a total $19 \%(\mathrm{n}=36)$ demonstrated twoor three-phase developments. As for interest regression, 18 percent of the respondents $(\mathrm{n}=34)$ showed a one phase regression, and $1 \%$ (two students) showed a two-phase regression. Among the group of regressed interest, it is noteworthy that all except one student were initially in the triggered situational interest phase. The development of interest could not be interpreted for eight students (4\%). An interesting observation is that almost all students with decreased interest (35/36, 97\%) ended up with phase 0 , that is, no interest; see quotations in Section 5.3 and discussion in Section 6.

Only a weak linear correlation existed between the initial interest and the observed change in interest (Pearson $\mathrm{r}=0.1736, \mathrm{df}=187, \mathrm{p}=0.01739$ two-tailed, the result is significant at $p<0.05$ ). This suggests that the development in interest was just as likely to occur for those students whose initial interest was in a less developed phase as for those students who were initially in a more developed phase, for instance, emerging individual interest.

An analysis of possible variation by gender was deemed inconclusive and omitted because there were only 17 female respondents. Moreover, we checked if the elapsed time between the workshop and the retrospective survey (see, Table 1) correlated with interest change. This correlation $(\mathrm{r}=0.135, \mathrm{df}=191, \mathrm{p}=0.0626)$ was not statistically significant at $p<0.05$.

Table 2 divides respondents into three categories according to our analyses: increased interest, no change in interest, and decreased interest. Moreover, the table 
Table 2

Interest - attribution categories (patterns) and explanation of the categories

\begin{tabular}{|c|c|c|c|}
\hline & \multicolumn{3}{|c|}{ Number of students and explanations of the categories } \\
\hline & Positive attribution & Neutral attribution & No attribution \\
\hline \multirow{2}{*}{$\begin{array}{l}\text { Increased } \\
\text { interest }\end{array}$} & $\mathrm{n}=102$ & $\mathrm{n}=6$ & $\mathrm{n}=3$ \\
\hline & $\begin{array}{l}\text { - Participant attributes his/her interest } \\
\text { increase at least partly to the work- } \\
\text { shop; see elaboration in Section 5.1. }\end{array}$ & $\begin{array}{l}\text { - Interest increased over time but } \\
\text { student couldn't say whether } \\
\text { this was due to the workshop }\end{array}$ & $\begin{array}{l}\text { - Interest would have } \\
\text { increased regardless } \\
\text { of the workshop. }\end{array}$ \\
\hline \multirow{2}{*}{$\begin{array}{l}\text { No change in } \\
\text { interest }\end{array}$} & $\mathrm{n}=22$ & $\mathrm{n}=14$ & $\mathrm{n}=5$ \\
\hline & $\begin{array}{l}\text { - Programming continues as a hobby } \\
\text { - View of computer science is possibly } \\
\text { changed } \\
\text { - New social connections through the } \\
\text { workshop are emphasized }\end{array}$ & $\begin{array}{l}\text { - No programming activity afte- } \\
\text { rwards, but computing career } \\
\text { remains a possibility } \\
\text { - Workshop did not affect pos- } \\
\text { sible future plans or interests }\end{array}$ & $\begin{array}{l}\text { - No interest before- } \\
\text { hand } \rightarrow \text { no change } \\
\text { - Workshop was con- } \\
\text { sidered a foray }\end{array}$ \\
\hline \multirow{2}{*}{$\begin{array}{l}\text { Decreased } \\
\text { interest }\end{array}$} & $\mathrm{n}=7$ & $\mathrm{n}=17$ & $\mathrm{n}=12$ \\
\hline & $\begin{array}{l}\text { - Student is shortly or temporarily en- } \\
\text { gaged in programming } \\
\text { - Interest finally regresses due to } \\
\text { practical and technical issues or } \\
\text { unfocused interest }\end{array}$ & $\begin{array}{l}\text { - Student enjoyed the workshop } \\
\text { but did not find time or } \\
\text { motivation to continue inde- } \\
\text { pendently }\end{array}$ & $\begin{array}{l}\text { - Student enjoyed the } \\
\text { workshop but found } \\
\text { that programming } \\
\text { was not "his/her } \\
\text { thing." }\end{array}$ \\
\hline
\end{tabular}

shows the extents to which respondents attributed their conditions of interest to the workshop within each of these three categories; see horizontal labels. This latter division was possible based on the students' response to a particular Likert scale question in the retrospective questionnaire, which asked whether the workshop was an incentive to subsequently continue with programming activities. Interest developments in the three categories on the vertical axis were interpreted based on multiple survey questions, using the time points of the pre-survey (the first workshop day) and the retrospective survey.

As for Table 2, our main research interest here is to observe how many students with increased interest attributed their interest development to the workshop. The observation is that the respondents with a positive interest development (the topmost row in Table 2) almost unanimously reported that the workshop affected their interest. Other interest - attribution patterns also were discovered. In the No change in interest category, although many students said the workshop was an incentive to continue programming, overall interpretations over multiple survey questions indicated that final interests did not differ from the initial ones. For instance, programming as a "side project" or initial lack of interest in programming simply continued. In the Decreased interest category, a student could mark that the workshop encouraged him or her to continue with programming (positive attribution), but when we interpreted the student's final interest over the multiple survey questions, we could rather find decreased interest. Some students thus showed 'fluctuations' in their relationship with programming, kind of temporary indications of continued or increased interest, regardless that overall students could demonstrate decreased interest. For more explanation of the patterns, see Table 2 . 
For many students, the workshop catalyzed their interest in CS and started a period of time that included voluntary computing activities, such as going to computing classes (in-school or extra-curricular), exploring programming literature, and engaging in various programming projects that they had not done before the workshop. It is, however, important to note that there were some students who reckoned that this catalysis never took place. In the following subsections, qualitative analyses in relation to these interest trajectories (increased interest, no change, regressed interest) are presented, and how the workshop's impact manifested itself in each of these trajectories are discussed.

As a general observation, students were quite active after the workshop with regard to programming. Two thirds $(65 \%)$ of the students reported having participated in modifying or creating new programs or games after the workshop, which is very similar to the findings from the authors' earlier longitudinal study (Lakanen and Isomöttönen, 2012). This activity was almost independent of prior exposure: earlier programming experience correlated moderately with post-workshop programming (Pearson $r=0.33$, $\mathrm{df}=186, p<0.00001$ two-tailed, the result is significant at $p<0.05$ ).

\subsection{Increased Interest}

Positive interest trajectories were demonstrated by 108 of 188 students $^{1}$ (57\%). This group comprised 58 students who were initially situationally interested (phase 1 or 2 ) and ended up in an individual interest phase (phase 3 or 4), 36 students whose interest developed within the situational phases (phase 1 to 2), and 12 students for whom the development occurred within the individual phases (phase 3 to 4). For the qualitative characterization below, the students demonstrating increased interest were treated as a single data set. The particular trajectory is mentioned in conjunction with each student quote. Later, the neutral and decreased interest trajectories are presented similarly.

\section{Independent reengagement with content.}

Repeated and continuous, selfsustained engagement were often attributed to the workshop. Students saw available opportunities to experiment and learn more about programming in particular, and even experienced what can be read as a state of ow during their "personal excursions" (see, Azevedo, 2006). In our interpretation, the workshop provided three anchors that facilitated students' reengagement with programming: content, artifact, and tools.

Content anchor: After introducing the students to fundamental CS concepts, the learners in more developed phases of interest became promoters and developers of their own interest. Here, the workshop's impact manifested itself in increased self-efficacy and in learners investing their time in developing knowledge of the disciplinary content initiated in the workshop. Although some topics such as sorting or path-finding algo-

${ }^{1}$ The total number of respondents was 197 . The interest trajectory could not be interpreted for nine students. 
rithms were only briefly illustrated, students were equipped with keywords and a starting point for improving their domain knowledge.

The workshop opened the world of programming for me and helped in the way to think about functions. I have later created small programs for my graphical calculator to make my life a little easier. I made, for example, a program that computes the intersection of a $3 D$ vector and a plane. (student $\# 172, P 1 \rightarrow P 3$ )

Students with individual interest (P3, P4) also described their post-workshop experiences in detail. These descriptions could be content-related (e.g., new techniques learned) or process-related (e.g., how the career in CS unfolded). This suggests that the learners had made connections with the content, and even taken pride in what they had achieved.

[After the workshop I have] continued making games with Game Maker, Unity, and other game engines for years until today. I'm also currently studying CS, where programming has a big role. (student $\# 61, P 2 \rightarrow P 4)$

The summer workshop set a foundation, and from that point on computing came in kind of naturally. I didn't even think about it that much. Also, I got an entrance into the university through a CS competition. (student \#89, P2 $\rightarrow$ P4)

Artifact anchor: The game artifacts created during the workshop provided the students with a point of reference - a concrete construct - that they could subsequently build on. Students either continued the game they had started in the workshop, or used it as a project template for next projects.

Before the workshop, I could hardly write any code. Today, however, game programming is my dearest hobby. In particular, the game I created in the summer course worked as a strong foundation for my current activities. I've used C\# and Java for both in-school and outof-school projects. (student \#29, P2 $\rightarrow$ P4)

I had not programmed before, but after the workshop I started to program games independently. I have done physics games and platformers with C\# and Visual Studio. I also took the workshop one more time. (student \#78, P1 $\rightarrow$ P3)

On reflection, students with increased interest seemed to find it relatively straightforward to modify the code after the workshop; even small changes to the previously crafted code enable quick visual response in the game development environment, which agrees with the notion of meaningful interactions (Scaico et al., 2017). These interactions make beginner programmers create a connection with the content and consequently 
sustain their engagement with it. Whereas games might have been the reason why many students got excited about the programming workshop in the first place, the actual artifact also served as a baseline for future interactions.

Tool anchor: The toolset was an important practical part of the interest continuum. The students who continued programming independently typically continued utilizing the tools that were used in the workshop. Interestingly, some students pointed out that they needed to learn some new tools (programming languages, libraries, environments, etc.) because the new ones served better with regard to their objectives.

I was inspired by C\# development, and used the Visual Studio license. Because Jypeli game engine did not have many features implemented in it, I moved to use XNA instead [which was not taught in the workshop, but which Jypeli was based on]. (student \#115, P3 $\rightarrow$ P4)

\section{Students start to ask for like-minded peers and mentors.}

Mentors, like-minded peers, or more formal classes seem to be important interest developers after the engaging workshop experience.

I found new, like-minded friends from the workshop, who are all now studying computer science. (student \#63,P2 $\rightarrow$ P4)

Furthermore, the impact of friends can be very prominent. This impact may show in students' career choices and even cause students to act in ways opposite to their personal interests. Hence, friends may reinforce and change individual's decisions. One student who ended up in studying CS followed his friend's choices during their time in middle and high school.
After the ninth grade I was enthusiastic about CS, but nevertheless went to a high school after my friends ${ }^{2}$. After one year my friend switched over to another [vocational] school [with a CS study line], and I thought that this would also be good for me. The workshop gave me clearer idea about programming, and made this decision easier. (student $\# 93, P 1 \rightarrow P 4)$

While the need for guidance and support after the workshop is often apparent, finding mentors or like-minded companions can take time. The following quote highlights that peer-support was discovered only when the student entered the university.

Alongside the school, I didn't have really time to learn coding myself. I found books and YouTube tutorials only after I had started my university studies, and now I also have new friends that are enthusiastic about programming. (student $\# 175, P 2 \rightarrow P 3$ )

\footnotetext{
${ }^{2}$ In Finland, high schools (upper secondary schools) have mostly a uniform curricula with no or minimal emphasis on CS
} 
During the workshop, teamwork and dynamic collaboration was a natural part of the working mode. Teams could be formed on-the-fly, for instance, two students could discuss about a particular issue in the code for a half an hour, and then carry on working more independently. Other teams could remain the whole week. After the workshop, self-paced, independent working at home meant the absence of mentors and peers, which felt frustrating to some students. The absence of this social dimension during the subsequent learning process was likely to hinder or slow down interest development.

I still feel like I would like to go back to the workshop and make programs together with the old and new mates. I don't have really any new contacts [to share my experience with.] (student $\# 150, P 1 \rightarrow P 2$ )

Finally, although the majority of the students with increased interest attributed their interest development to the workshop, nine students reported that this increase occurred regardless of the outreach. One theme here was that the student did not see programming as a hobby during that time, and then did not see workshop as an incentive to programming, although the subsequent actions could indicate some increase in interest.

I can't say that I'm a programming hobbyist, so I don't see that the summer workshop affected my interest. However, I have chosen voluntary coding classes in JavaScript, PHP, etc., and choosing these classes was a bit easier because I already knew something about programming. (student $\# 192, P 1 \rightarrow P 2$ )

Another, reoccurring theme was that the student was already interested in CS in a way that the workshop could not contribute to this interest.

I have always been interested in programming and I had been programming before attending the workshop. I did learn something new, but it did not affect my take on programming. (student \#124, $P 3 \rightarrow P 4)$

The workshop was interesting, but [. . ] it did not have an effect in terms of engagement, at least at a conscious level. I want to know how and why a particular algorithm or a function works exactly. One week is not enough to get an understanding why some solution is the best. (student $\# 127, P 2 \rightarrow P 4$ )

\subsection{No Change in Interest}

In this group, the current interest phase was the same as it was prior to the workshop. A total of 44 out of 188 students (23\%) exhibited neutral interest trajectories. It was clearly the most common case that a student remained in the triggered situational inter- 
est phase, phase 1. Only ten students remained in phase 2, while a couple of students remained in phase 3 or phase 0 . For the students in the early phases of interest, two main reasons explain why interest eventually remained in its initial phase. First, the lack of personal ideas for what to program led to the lack of motivation, which is illustrated below.

From time to time, I have tried to write Java or C, but then run out of motivation. The reason for that [loss of motivation] might be that I do not really have anything that I would like to program. (student \#28 P1 $\rightarrow$ P1)

Second, technical challenges thwarted incipient engagement. Especially in the early phases, interest seems to be extremely vulnerable to technical issues. Even though students were given instructions on how to install the software tools that were used in the workshop on their home computers, some students still faced challenges that they were unable to solve themselves, and their interest remained dormant in phase 1 .

I have not done any programming, because I could not install the development environment to my computer. I would be interested [to continue programming], though. (student $\# 142, P 1 \rightarrow P 1$ )

One student whose interest remained in an individual phase (phase 3) had quite significant amount of previous programming exposure, and felt that the workshop did not contribute to his interest. A handful of students remained in the "zero phase" (no interest); their reason for participation was purely experimental or even enforced by parents.

It did not impact my interest per se, but it was nice to meet like-minded people. (student $\# 98, P 3 \rightarrow P 3$ )

I took the course because my mom told me to. It was fun, but I wasn't interested in CS beforehand, and not really much after that either. (student $\# 106, P 0 \rightarrow P 0$ )

Even though the interest might have ended up in the same phase where it started from, the present longitudinal study with its retrospective questions revealed some fluctuations. There were fluctuations between the interest phases for those students who had multiple subjects of interest; for example, interest could have developed one or more phases, go into a dormant state, and then regress, as the student discovered a new domain of interest.

I learned a lot of new things [in the workshop], and I've also done a couple of 2D space shooter games afterwards. I managed to continue with the things I learned for a while, but then I got onto study another subject. Currently, I've got more into cyber security. (student \#141, $P 2 \rightarrow P 2)$ 


\subsection{Decreased Interest}

Decreased interest trajectories concerned 36 out of 188 students (19\%): 33 decreased from phase 1 to phase 0 , two decreased from phase 2 to phase 0 , and one decreased from phase 2 to phase 1 . Thus, none of the students who originally demonstrated individual interest (phase 3 or phase 4) encountered interest decrease. Factors that underlay these decreases were the excessive challenge perceived and unrealistic expectations towards programming. In particular, it came as a surprise that programming requires sustained, focused attention, and that constructing programs can take quite a lot of time. However, none of the students expressed that their interest decreased because of the outreach event. The excessive challenge in constructing programs is highlighted in the following quotes.

Programming is hard, even though writing code was made a little simpler [by using a game engine]. (student $\# 91, P 1 \rightarrow P 0$ )

I pondered about focusing on games [in my future studies] but I decided that it wasn't my thing; it was too difficult to make games. (student $\# 90, P 2 \rightarrow P 0)$

Although the game engine made it significantly easier to create interactive games, some students found that the idea - coding - result-cycle was still too long, and they would have liked to see the concrete product more quickly. The following excerpt highlights these unrealistic expectations towards programming.

I felt that I am too impatient. The results didn't feel rewarding enough compared to the amount of work that it required. I was more interested in the visual [design] part. (student $\# 183, P 1 \rightarrow P 0$ )

Here, the student noticed decreased interest already during the time of workshop. Furthermore, students participated out of curiosity and did not have plans to continue with programming after the workshop. In such cases, the impact of the workshop remained minuscule and students' interest decreased.

The workshop had no impact on me. I had not done any programming before. I just wanted to try out what it was like. (student \#194, $P 1 \rightarrow P 0)$

\subsection{Pre-workshop Programming Experience}

Prior programming experience correlated little with a change in interest phases (Spearman's rank correlation coefficient $r=0.241, \mathrm{df}=187, \mathrm{p}=0.001033$ two-tailed, the result is significant at $p<0.05$ ). Here, the single most notable difference between the groups was that in the "no experience" group there were relatively more those whose interest had regressed one phase. This is depicted in Fig. 3. Other than that, pre-workshop program- 


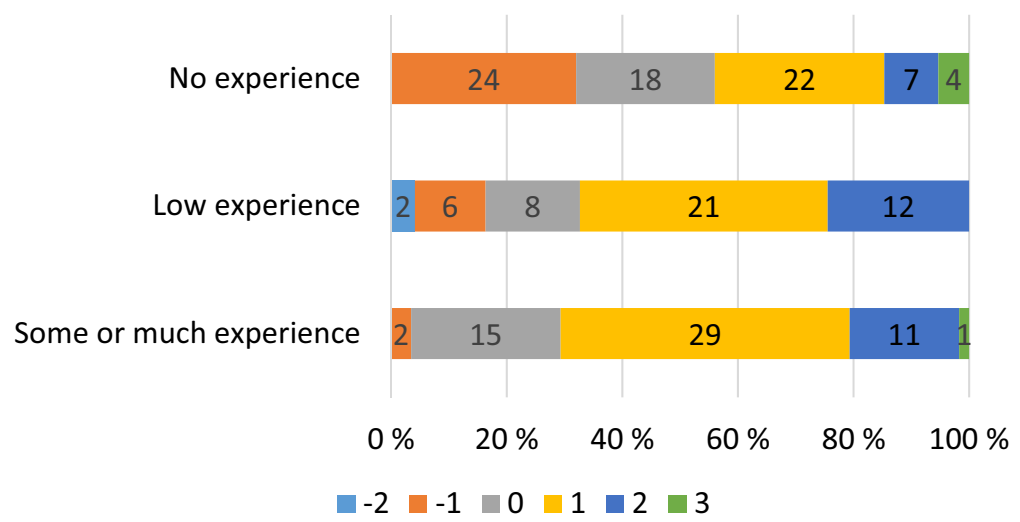

Fig. 3. Frequencies of the interest change categories in relation to earlier programming experience $(-2=$ two phase interest decrease, $-1=$ one phase interest decrease, $\ldots, 3=$ three phase interest increase). For example, there were 22 students with no earlier programming experience whose interest increased one phase and 6 students with low experience whose interest decreased one phase.

ming experience itself did not seem to contribute much to the overall interest change over time. For the purpose of this correlation analysis, earlier programming exposure was recoded as follows: $1 \rightarrow$ no experience, $2 \rightarrow$ some experience, 3 . . 5 $\rightarrow$ moderate or more experience.

Programming experience prior to the workshop was mostly non-existent or low, $40 \%$ had no experience at all, while the average was 2.1 on a five-step Likert scale $(1=$ none, $2=$ little, . . ., 5=much experience). The students had also a possibility to elaborate on their experiences through a separate, open-ended question, which revealed some variation, for instance, in how the word "little experience" had been interpreted. Students with little experience described that they had written or tried to write a small program, a script, or had "modded" a computer game (modified rules of an existing game to change the underlying game logic or the storyline). In contrast, those who had made a coherent whole program - even if it was a small one - typically marked their earlier experience with ' 3 ' or higher, and were verbose in explaining how their program solved a particular problem. Taken together, it seems safe to argue that 1 or 2 indicated at most fleeting attendance to programming.

\section{Discussion}

This study supports the claim that participating in a computing outreach event has a long-term impact on the development of interest in computing. Positive interest development concerned $57 \%$ of the students, while $23 \%$ encountered no change in interest, and $20 \%$ encountered interest regression. Most of the students with a positive interest trajectory (92\%) attributed the development to the outreach event at least partly. With regard to the four-phase model of interest development, the typical manifestation of in- 
terest development was an increase from phase 1 (triggered situational interest) to phase 2 (maintained situational interest) or to phase 3 (emerging individual interest), as these equally represented the final interest.

Outreach experience with practical hands-on activities can provide anchors for selfdirected reengagement. These anchors work as points of reference that students can lean on while learning programming and constructing their own programs. Moreover, the anchors can even help in sustaining or developing interest, increase self-efficacy, and scaffold learning of more complex programming topics. In this study, three anchors were found: content, artifact, and tools. The domain knowledge lectured and shared otherwise provided the content anchor, the concrete game constructs worked as the artifact anchor, and the programming environment provided the tool anchor.

Interest development has a tendency to benefit from continuous support. Even in an individual interest phase, interest often needs support to keep developing further (Renninger and Hidi, 2016, p. 3). The present work revealed that even though it was possible that outreach as a one-off experience was able to generate interest, novice programmers subsequently longed for like-minded peers or mentors. This finding concurs with Vrieler et al. (2017), who posited that "exposure alone is no guarantee to engage young people in CS and in particular programming." Our qualitative examination hinted that the absence of like-minded peers or mentors can lead to frustration and suppress interest. However, students who ended up in more developed phases of interest were also more likely to obtain support from mentors or peers. These indications are in line with the work by Ko and Davis (2017), which reported that teens who were developing a relationship with mentors reported stronger interest in computing than students without such condition.

On the other hand, interest is particularly vulnerable to technical and practical issues in the situational phases (Renninger and Hidi, 2011, p. 178). This seems to be particularly relevant in the field of programming: Our qualitative data suggests that without support experienced difficulty in learning programming, and relatedly impatience in witnessing results of one's effort, may cause the student to give up and interest to regress into the phase of no interest. All students with decreased interest were originally in situational phases, which highlights the fragility of situational interest.

Finally, reflections on the two key questions related to the present outreach setting are provided: game theme and gender imbalance. The workshop model heavily relied on games in terms of the programming tool that was designed to serve as a game engine and a library, but also in terms of providing a medium to contextualize the learning content. The workshop was initially targeted at young students, building on the assumption that the majority of Finnish schoolchildren are somewhat active game players. The idea of using games as a medium to reinvigorate the academic interests of participants seemed obvious, and the workshop did indeed mostly attract those who were initially interested in playing games. Anecdotal evidence from the outreach instructors also suggests that workshop participants greatly enjoyed working on their own projects. Game-based learning has been found to result in effective learning, and improve student enjoyment, engagement, and interest in the learning process, regardless of gender (Papastergiou, 2009). Further, game-based learning has been found to be quite effective at the university level (Vihavainen et al., 2014). Game-themed instruction alone is not, however, 
a silver bullet. First, the emphasis on game development may have been one reason alienating female participants. Second, for some students, the game-themed approach seemed to deliver a too narrow first impression about the nature of learning computer science, and convey unrealistic expectations about drawing big results with little effort. It can be speculated that these issues can occur especially if game-themed instruction is associated too tightly with playing or consuming computer games by the participants. For one, learning programming is laborious; it is not possible to "pay to win" in learning like it can be done in many games. Therefore, it may be helpful to outreach campaigns to display not only games but multiple contexts of programming, and even incorporate different contexts into the assignments of a single workshop.

When studying students' motivations to enter computer science or computing studies at a university, gender still emerges as a significant factor. Even though there is growing public attraction to learning to program, and a multitude of outreach activities have aimed for broadening participation, the number of women involved in computing activities remains low (Decker and McGill, 2017). McGill et al. (2016) concluded that boys may receive outreach activities more favorably than girls, and that this may be due to the types of activities that inconsistently influence youngsters' views. Even though the present outreach setting aimed at activating schoolchildren without a specific target group, the prominent gender imbalance was also the case here. A girls-only workshop was piloted in 2016, which was popular at first, but already the second try failed to attract enough participants, and the whole concept was then canceled. The project has not been able to close the gender gap through its workshop design. One of the flaws of this study is that due to the low number of female participants in the workshops, there were only a handful of female respondents. In this connection, the reader should be cautious in making broad generalizations or interpretations of the transferability of the study. For the future initiatives - whether conducted by us or others - it is essential to carefully consider the previous research results for better engagement and overall impact across genders. High school aged girls generally seem to view CS as boring (Anderson et al., 2008) and identify CS with its traditional subjects (hardware, algorithms, programming) (Papastergiou, 2008). However, those who persist in CS have reported on peer support (Margolis and Fisher, 2003), experience the sense of accomplishment that arises from solving problems with computers (Almstrum, 2003), and see computers as useful for expression and reject the stereotype of a computer geek (Margolis and Fisher, 2003). Other studies have found that women who persist see the intrinsic value of computers. Learning and working in pairs on the computer is also related to retention in computer science courses (McDowell et al., 2002).

\section{Conclusions}

The present study has demonstrated how interest develops over time after a one-week game programming outreach workshop. Our findings indicate that when interest towards programming has been previously triggered, an outreach event can further develop this interest to a more developed phase by providing possibilities for independently reen- 
gaging with content. On the other hand, the workshop can offer a platform for social interactions, so that students can encounter like-minded peers and find mentors. These connections can significantly support further engagement in programming. When examining the decreased interest trajectories, our results concur with the earlier scientific literature on that programming is difficult and takes a lot of patience and perseverance to master. Excessive challenge, unrealistic expectations or technical issues can quickly repress interest in an early, situational phase.

\section{References}

Almstrum, V.L. (Sep. 2003). What is the Attraction to Computing? Commun. ACM, 46(9), 51-55.

Anderson, N., Lankshear, C., Timms, C., Courtney, L. (May 2008). 'Because It's Boring, Irrelevant and I Don'T Like Computers': Why High School Girls Avoid Professionally-oriented ICT Subjects. Comput. Educ., 50(4), 1304-1318.

Azevedo, F.S. (Apr 2006). Personal Excursions: Investigating the Dynamics of Student Engagement. International Journal of Computers for Mathematical Learning, 11(1), 57-98.

Bartlett, J.E., Kotrlik, J.W., Higgins, C.C. (Spring 2001). Organizational research: Determining appropriate sample size in survey research. Information Technology, Learning, and Performance Journal, 19(1), 43-50.

Beh, J., Pedell, S., Doube, W. (2015). Where is the I in iPad?: The Role of Interest in Older Adults' Learning of Mobile Touch Screen Technologies. In: Proceedings of the Annual Meeting of the Australian Special Interest Group for Computer Human Interaction. ACM, 437-445, doi: 10.1145/2838739.2838776.

Burns, H.D., Lesseig, K., Staus, N. (2016). Girls' Interest in STEM. In: Frontiers in Education Conference (FIE). IEEE Computer Society, 1-5, doi: 10.1109/FIE.2016.7757645.

Decker, A., McGill, M.M. (2017). Pre-College Computing Outreach Research: Towards Improving the Practice. In: Proceedings of the 2017 ACM SIGCSE Technical Symposium on Computer Science Education. SIGCSE '17. ACM, New York, NY, USA, 153-158.

Dousay, T.A. (2014). Multimedia Design and Situational Interest: A Look at Juxtaposition and Measurement. In: Educational Media and Technology Yearbook. Springer, 69-82, doi: 10.1007/978-3-319-06314-0 5.

Erete, S., Pinkard, N., Martin, C.K., Sandherr, J. (2016). Exploring the Use of Interactive Narratives to Engage Inner-City Girls in Computational Activities. In: Research on Equity and Sustained Participation in Engineering, Computing, and Technology (RESPECT). 1-4, doi: 10.1109/RESPECT.2016.7836168.

Henriksen, E.K., Jensen, F., Sjaastad, J. (2015). The Role of Out-of-School Experiences and Targeted Recruitment Efforts in Norwegian Science and Technology Students' Educational Choice. International Journal of Science Education, Part B, 5(3), 203-222, doi: 10.1080/21548455.2014.900585.

Hidi, S., Renninger, K.A. (2006a). The Four-Phase Model of Interest Development. Educational Psychologist, 41(2), 111-127, doi: 10.1207/s15326985ep4102 4.

Hidi, S., Renninger, K.A. (Jun. 2006b). The Four-Phase Model of Interest Development. Educational Psychologist, 41(2), 111-127.

Ko, A.J., Davis, K. (2017). Computing Mentorship in a Software Boomtown: Relationships to Adolescent Interest and Beliefs. In: Proceedings of the 2017 ACM Conference on International Computing Education Research. ICER '17. ACM, New York, NY, USA, 236-244.

Krapp, A. (2002). Structural and dynamic aspects of interest development: theoretical considerations from an Ontogenetic Perspective. Learning and Instruction, 12(4), 383-409.

Lakanen, A., Isomöttönen, V. (2012). Life Two Years After a Game Programming Course: Longitudinal Viewpoints on K-12 Outreach In: Proceedings of the 2012 ACM SIGCSE Technical Symposium on Computer Science Education. SIGCSE '12. ACM, New York, NY, USA, 481-486.

Margolis, J., Fisher, A. (2003). Unlocking the clubhouse: Women in computing. MIT press.

McDowell, C., Werner, L., Bullock, H., Fernald, J. (2002). The effects of pairprogramming on performance in an introductory programming course. ACM SIGCSE Bulletin, 34(1), 38-42.

McGill, M.M., Decker, A., Settle, A. (2015). Does Outreach Impact Choices of Major for Underrepresented Undergraduate Students? In: Proceedings of the Eleventh Annual International Conference on International Computing Education Research. ICER '15. ACM, New York, NY, USA, 71-80. 
McGill, M.M., Decker, A., Settle, A. (Jun. 2016). Undergraduate Students' Perceptions of the Impact of PreCollege Computing Activities on Choices of Major. Trans. Comput. Educ., 16(4).

Papastergiou, M. (2008). Are Computer Science and Information Technology still masculine fields? High school students' perceptions and career choices. Computers \& Education, 51(2), 594-608.

Papastergiou, M. (Jan. 2009). Digital Game-Based Learning in high school Computer Science education: Impact on educational effectiveness and student motivation. Computers \& Education, 52(1), 1-12.

Potvin, P., Hasni, A. (2014). Interest, Motivation and Attitude towards Science and Technology at K-12 Levels: A Systematic Review of 12 Years of Educational Research. Studies in Science Education, 50(1), 85-129, doi: 10.1080/03057267.2014.881626.

Renninger, K.A., Hidi, S. (Jul. 2011). Revisiting the Conceptualization, Measurement, and Generation of Interest. Educational Psychologist, 46(3), 168-184.

Renninger, K.A., Hidi, S.E. (2016). The power of interest for motivation and engagement. Routledge.

Reschly, A.L., Christenson, S.L. (2012). Jingle, Jangle, and Conceptual Haziness: Evolution and Future Directions of the Engagement Construct. In: Christenson, S.L., Reschly, A.L., Wylie, C. (Eds.), Handbook of Research on Student Engagement. Springer US, 3-19.

Scaico, P.D., José, R., Dias, J.J.L. (2017). Analyzing How Interest in Learning Programming Changes During a CS0 Course: A Qualitative Study with Brazilian Undergraduates. In: Proceedings of the 2017 ACM Conference on Innovation and Technology in Computer Science Education. ITiCSE '17. ACM, New York, NY, USA, 16-21.

Sweller, J. (Apr. 2006). The worked example effect and human cognition. Learning and Instruction, 16(2), $165-169$.

Vihavainen, A., Airaksinen, J., Watson, C. (2014). A Systematic Review of Approaches for Teaching Introductory Programming and Their Inuence on Success. In: Proceedings of the Tenth Annual Conference on International Computing Education Research. ICER '14. ACM, New York, NY, USA, 19-26.

Vrieler, T., Nylén, A., Cajander, . (Oct. 2017). What computing instructors did last summer: Experiences and lessons learned. In: 2017 IEEE Frontiers in Education Conference (FIE). IEEE Computer Society, 1-8.

Wall, S. (2008). Easier said than done: Writing an autoethnography. International Journal of Qualitative Methods, 7(1), 38-53.

A.J. Lakanen is a university teacher at the Faculty of Information Technology, University of Jyväskylä (Finland). His research interests include computing education research, K-12 computing education, introductory programming, game programming, outreach, interest development, and mixed methods.

V. Isomöttönen is a senior lecturer at the Faculty of Information Technology, University of Jyväskylä (Finland). His research has focused on topics such as project-based learning, programming education, outreach, and educational technology. 


\section{Appendix}

\section{Survey questions}

The questions in the pre-questionnaire and retrospective questionnaire are given in the following.

\section{Pre-questionnaire}

1. I have made / designed games with or without a computer (yes/no). If yes, describe what have you done (open-ended).

2. I have previous programming experience (Likert, $1=$ none, . . .5=much experience). If yes, describe your activities related to programming (open-ended).

3. I came to the workshop, because. . . (multiple-choice, 9 choices, e.g., I want to learn programming, I am interested in games, etc.).

4. I will apply for a major in computer science (Likert)

5. I am interested in working in a job related to programming in the future (Likert).

\section{Retrospective questionnaire}

1. After the summer workshop I have. . .

- done programs or games OR modified a program or game (Likert).

- done some other activities related to programming (Likert).

2. Describe your activities related to programming.

3. Workshop encouraged me to do programming, self-directed or with guidance (Likert).

4. I have done programming activities that I did NOT do before the workshop (Likert).

5. Describe how the workshop affected you with regard to programming (open-ended).

6. Describe the feelings the workshop woke in you (content, surroundings, social context, etc.) .

7. Currently, I'm studying in. . (university, high school, basic education, not studying; name of the institution).

- If in higher education: Major and starting year.

- Programming workshop had an impact in my studying plans (Likert; two similar questions).

- I would have chosen differently if it wasn't for the programming workshop (Likert).

- If not in higher education:

- Do you plan to apply to higher education? (Likert). If yes, enter which university, major (open-ended).

- Programming workshop had an impact on future my studying plans (Likert).

- I think I would choose differently if it wasn't for the programming workshop (Likert).

8. How the workshop affected your choices or study plans? (open-ended).

9. Has the workshop helped you in your studies? (open-ended). 
